\title{
Angioscopic observation of an atherosclerotic coronary aneurysm without yellow plaque
}

\author{
Yasuyuki Toyama, Sei Komatsu, Mitsuhiko Takewa, Kazuhisa Kodama
}

Cardiovascular Center, Osaka Gyoumeikan Hospital, Osaka, Japan

\section{Correspondence to} Dr Sei Komatsu,

plaquemap@yahoo.co.jp

Accepted 23 June 2017

\section{DESCRIPTION}

A-58-year-old man with diabetes mellitus was admitted to our hospital with angina following physical effort. Coronary CT angiography (CCTA) revealed a saccular coronary aneurysm at the left main trunk bifurcation and a significant stenosis at the middle portion of the calcified left anterior descending artery (LAD) (figure 1). Invasive coronary angiography showed a large coronary aneurysm $(12.3 \times 11.0 \mathrm{~mm})$ arising from the ostial LAD and stenoses in the middle of the LAD and in the middle of the left circumflex artery (figure 2). Intravascular ultrasound showed a severely calcified LAD, as shown on CCTA; however, it failed to reveal the entire picture with regard to the aneurysm because of the limited echo depth. Non-obstructive
A

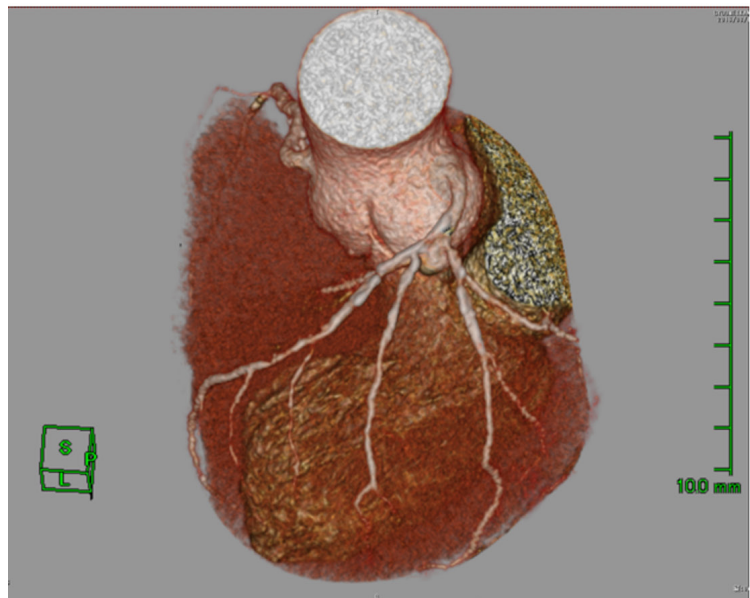

B

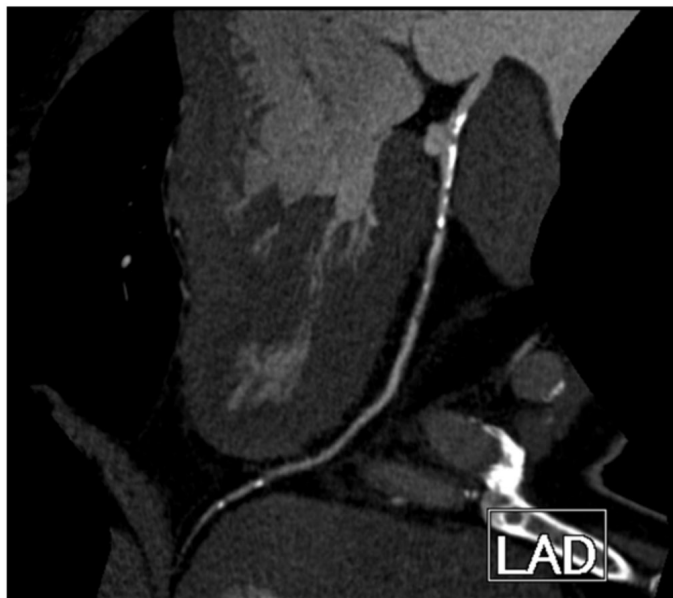

Figure 1 Coronary CT angiography images. (A) The volume rendering image shows a saccular coronary aneurysm at the left main trunk bifurcation. (B) The curved multiplanar reformation image of the left anterior descending coronary artery shows a significant stenosis at the middle portion.

A

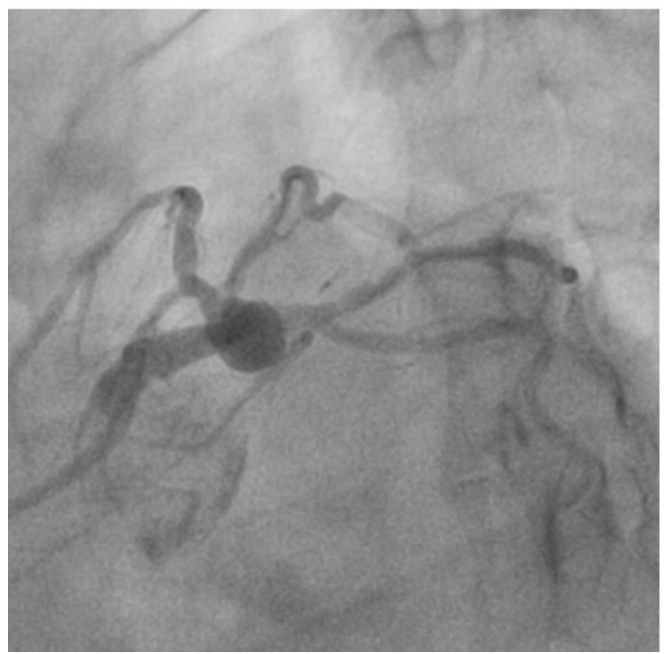

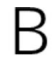

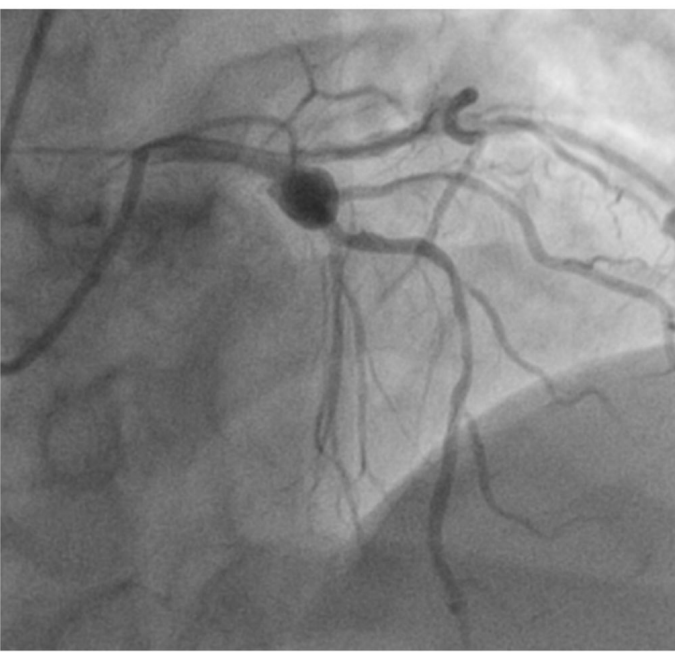

Figure 2 Invasive coronary angiographic images. (A) Coronary angiogram in the left anterior oblique caudal view shows an aneurysm with a diameter of $12.3 \times 11.0 \mathrm{~mm}$. (B) The cranial view shows a significant stenosis in the middle of the left anterior descending coronary artery and in the middle of the diagonal branch. 
Images in...

\section{A}

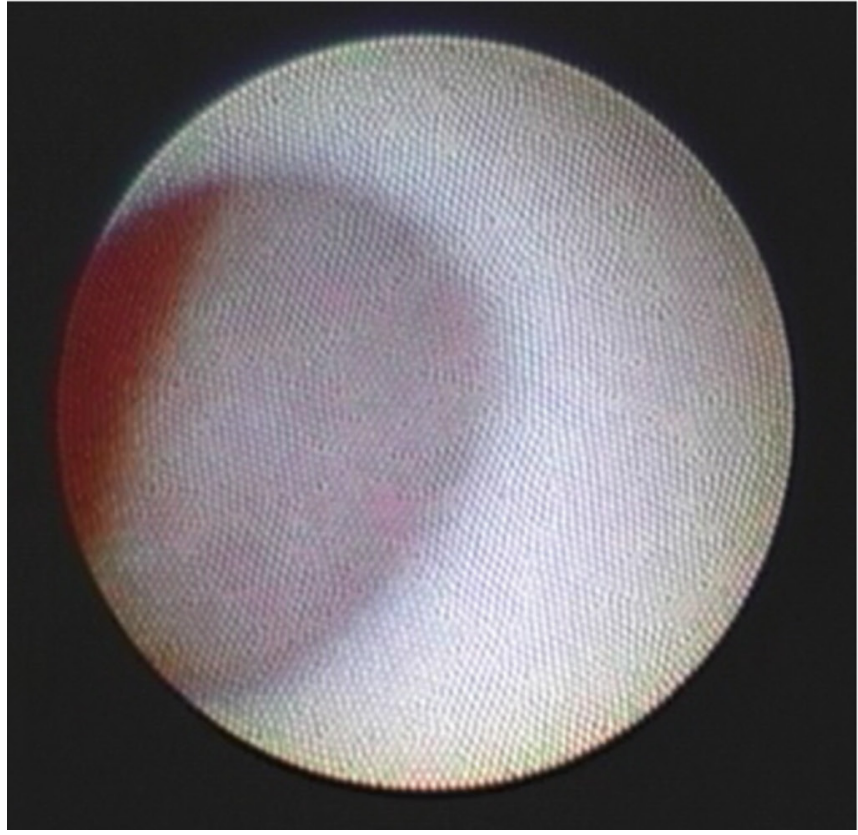

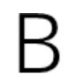

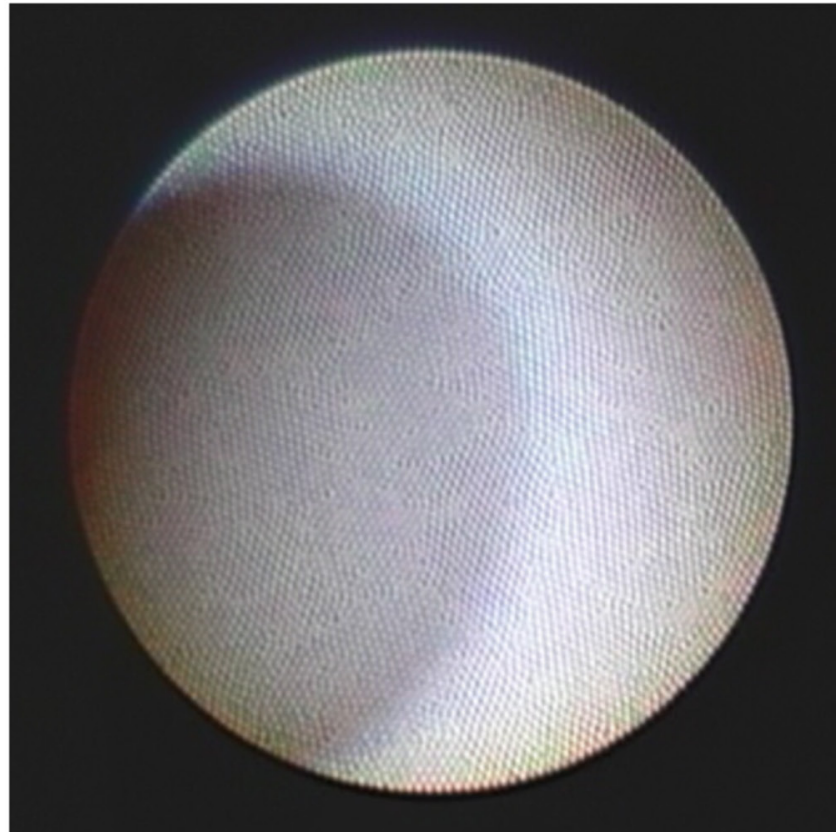

Figure 3 (A) The angioscopic image of the coronary aneurysm shows a rough, salmon-pink coloured surface without the presence of thrombus or atheromatous yellow plaque. (B) The angioscopic image shows a normal-sized coronary artery proximal to the aneurysm with a white surface.

\section{Learning points}

Very few previous studies have reported coronary artery aneurysms in fine detail, despite the fact that there is a significant risk of thrombogenicity leading to ischaemia or infarction.

- Non-obstructive angioscopy allowed visibility of a rough salmon-pink coloured surface inside the atherosclerotic coronary aneurysm.

- The patient's postoperative course has been uneventful after coronary artery bypass surgery and ongoing administration of aspirin.

angioscopy $(\mathrm{NOA})^{1}$ was performed to investigate the intimal injury of the aneurysm and demonstrated a rough, salmon-pink coloured surface without the presence of thrombus or atheromatous yellow plaque ${ }^{2}$ (figure 3 ).

Thrombogenicity inside a coronary aneurysm is known to cause ischaemia or myocardial infarction. ${ }^{3}$ Administration of antiplatelet therapy (aspirin $100 \mathrm{mg} /$ day) was continued beyond the coronary artery bypass graft for LAD to avoid thrombosis.
The patient's postoperative course was uneventful. Our case shows that NOA may play a role in estimating the preoperative thrombosis risk in patients with coronary artery aneurysm.

Contributors YT and MT planned and designed the study. YT and SK paticipated in the conduct. YT wrote the manuscript. YT, SK, MT and KK gave final approval of the version published. SK was responsible for the overall content as guarantor.

Competing interests KK is the president of Inter-tec Medicals and originally developed non-obstructive angioscopy. SK is a technical consultant for Nemoto Kyorindo. YT and MT declared no conflict of interests.

Patient consent Obtained.

Provenance and peer review Not commissioned; externally peer reviewed.

(c) BMJ Publishing Group Ltd (unless otherwise stated in the text of the article). All rights reserved. No commercial use is permitted unless otherwise expressly granted.

\section{REFERENCES}

1 Komatsu S, Ohara T, Takahashi S, et al. Improving the visual field in coronary artery by with non-obstructive angioscopy: dual infusion method. Int J Cardiovasc Imaging 2017;33:789-96.

2 Komatsu S, Ohara T, Takahashi S, et al. Early detection of vulnerable atherosclerotic plaque for risk reduction of acute aortic rupture and thromboemboli and atheroemboli using non-obstructive angioscopy. Circ J 2015;79:742-50.

3 Baman TS, Cole JH, Devireddy CM, et al. Risk factors and outcomes in patients with coronary artery aneurysms. Am J Cardio/ 2004;93:1549-51. 
Copyright 2017 BMJ Publishing Group. All rights reserved. For permission to reuse any of this content visit http://group.bmj.com/group/rights-licensing/permissions.

BMJ Case Report Fellows may re-use this article for personal use and teaching without any further permission.

Become a Fellow of BMJ Case Reports today and you can:

- Submit as many cases as you like

- Enjoy fast sympathetic peer review and rapid publication of accepted articles

Access all the published articles

Re-use any of the published material for personal use and teaching without further permission

For information on Institutional Fellowships contact consortiasales@bmjgroup.com

Visit casereports.bmj.com for more articles like this and to become a Fellow 